\title{
Genetic aspects of a new mutation (sal-s) to sex-linked imperfect albinism in chickens
}

\author{
FG Silversides *, RD Crawford \\ Department of Animal and Poultry Science, \\ University of Saskatchewan, \\ Saskatoon, Saskatchewan SYN OWO, Canada
}

(Received 8 January 1990; accepted 22 August 1990)

Summary - A mutation to imperfect albinism occurred in a line of chickens that had been closed for 15 generations. This is the sixth such mutation to be described in chickens, and similar mutations have occurred in a variety of other avian species. The mutation is sexlinked, recessive, and linked to the $s^{+}$locus, as well as to the $s^{a l}$ obtained from the University of Massachusetts. The gene symbol $s^{a l-s}$ is proposed for this new mutation to distinguish it from other $s^{a l}$ genes in chikens. The occurrence of a number of individuals mosaic for ocular pigmentation in matings involving $s^{a l-s}$ supports the hypothesis that the mutation is the result of integration of a genetic element in or near the $s^{+}$locus.

$s^{a l-s} /$ albino / chicken / mutation

Résumé - Aspects génétiques relatifs à une nouvelle mutation $\left(s^{a l-s}\right)$ pour l'albinisme imparfait lié au sexe chez la poule. Une mutation pour un albinisme imparfait est apparue dans une lignée de poulets qui était restée fermée depuis 15 générations. Il s'agit de la sixième mutation de ce genre à avoir été décrite chez la poule; des mutations ont été observées dans diverses autres espèces aviaires. Le gène mutant est lié au sexe, il est récessif et lié au locus $s^{+}$de même qu'un gène $s^{\text {al }}$ obtenu de l'Université de Massachussets. Le symbole $s^{a l-s}$ est proposé pour ce nouveau gène pour le distinguer d'autres gènes $s^{\text {al }}$ chez le poulet. L'apparition d'un certain nombre d'individus mosaïques pour la pigmentation oculaire dans des croisements incluant $s^{\text {al-s }}$ plaide pour l'hypothèse selon laquelle la mutation est le résultat de l'intégration d'un élément génétique à l'intérieur ou à proximité du locus $s^{+}$.

$s^{a l-s} /$ albinisme / poulet / mutation

\footnotetext{
* Present address: Département de Zootechnie, Université Laval, Québec, Canada, G1K $7 \mathrm{P} 4$
} 


\section{INTRODUCTION}

A sex-linked locus with three alleles is primarily responsible for control of pigment production on the non-black areas of the fowl. The wild-type $\left(s^{+}\right)$allele allows full expression of phaeomelanin, the silver $(S)$ allele prevents its deposition and the allele for imperfect albinism allows only limited production of all types of melanin. The literature describes at least 5 mutations to sex-linked imperfect albinism in the chicken (Mueller and Hutt, 1941; Hutt and Mueller, 1943; Champion, 1958; Werret et al, 1959). In 1983, 15 albino individuals, all female, were found among 700 progeny of a flock mating involving 12 sires and 30 dams, suggesting the presence of a sex-linked gene. In pedigreed matings, one of these sires yielded 15 albino and 42 colored individuals when mated to Brown Leghorn females. Again, all albinos were females and further studies of the new mutation are based on descendents of this sire. The albino phenotype is similar to that of other imperfect albinos. Briefly, melanin pigmentation in the down and feathers is reduced to leave a ghost pattern, and the eyes are red at hatching but darken with age. The gene symbol $s^{a l-s}(s=$ Saskatchewan) is proposed for this gene to differentiate it from the others.

Similar mutations have occurred in other avian species: Japanese quail (Lauber, 1964; Sittman et al, 1966), ring-neck pheasants (Bruckner, 1969), turkeys (Hutt and Mueller, 1942) and budgerigars (Kokemüller, 1936 as cited by Hutt and Mueller, 1942). A cinnamon mutation known to canary fanciers (Dodwell, 1976) would also appear to be sex-linked imperfect albinism. This report summarizes segregation data from crosses involving the $s^{a l-s}$ gene and describes the occurrence of mosaic individuals among the offspring of crosses involving this gene.

\section{MATERIALS AND METHODS}

During the course of investigations of the new gene for imperfect albinism, a number of lines of chickens were used. The line in which the gene mutation occurred is a single gene marker stock segregating for $O$ and $P$, formed from Aracauna, Brown Leghorn and Rhode Island Red breeds in 1967 and 1968 and maintained as a closed flock since then. The albino meat and layer lines were developed at the University of Saskatchewan and segregate for $s^{a l-s}$ (Silversides and Crawford 1990a, 1990b). Fertile eggs from the University of Massachusetts produced the males that carried the $s^{a l}$ gene maintained there. This gene was probably one of the mutations first described by researchers at Cornell University (Smyth, 1987, personal communication), hence the gene symbol $s^{a l-c}(c=$ Cornell) will be used to indicate this origin. The pure breeds used (Brown Leghorn, White Leghorn, Light Sussex, White Wyandotte, Barred Plymouth Rock and Rhode Island Red) were from the collection of antique stocks kept at the University of Saskatchewan. Most have been maintened as unselected closed flocks for 20 or more generations.

In the course of these studies, 47 sets of matings were made, involving all 6 possible albino and non-albino genotypes (table I). Heterogeneity $\chi^{2}$ analyses (Strickberger, 1976) were performed on data sets making up the three mating combinations expected to produce both genotypes with expected values based on the hypothesis of a single sex-linked gene. The three other mating combinations were expected to produce progeny of only one phenotype. The sex of 5421 individuals was 
determined. Heterogeneity $\chi^{2}$ analysis of the data allowed pooling within mating type.

Table I. Segregation data from albino trials ${ }^{1}$

\begin{tabular}{lrcrrrrr}
\hline Mating & & \multicolumn{1}{c}{ Albino } & & Non-albino & Mosaic & Total & $\chi^{2}$ \\
\hline$s^{a l} s^{a l} \times s^{a l} /-$ & 777 & $(792.0)^{2}$ & 15 & $(0)$ & 12 & 804 & - \\
$s^{a l} s^{a l} \mathrm{X}+/-$ & 477 & $(492.0)$ & 507 & $(492.0)$ & 5 & 989 & 0.91 \\
$+s^{a l} \mathrm{X} s^{a l} /-$ & 1714 & $(1762.5)$ & 1811 & $(1762.5)$ & 29 & 3554 & 2.67 \\
$+s^{a l} \mathrm{X}+/-$ & 797 & $(853.8)$ & 2619 & $(2561.3)$ & 13 & 3429 & $5.03^{*}$ \\
$++\mathrm{X} s^{a l} /-$ & 0 & $(0)$ & 234 & $(234.0)$ & 0 & 234 & - \\
$++\mathrm{X}+/-$ & 2 & $(0)$ & 684 & $(684.0)$ & 0 & 686 & - \\
& 3767 & & 5870 & & 59 & 9696 & \\
\hline
\end{tabular}

${ }^{1}$ The symbol + is used to indicate both $S$ and $s^{+}$alleles. ${ }^{2}$ Numbers in brackets represent the values expected with a sex-linked recessive gene. Mosaic individuals are included in the totals but not the expected values. ${ }^{*} P<0.05$.

Males with the genotype $S / s^{a l-s}$ were crossed to both $s^{a l-s} /-$ and $s^{+} /-$females to test for linkage of $s^{a l-s}$ with the $s^{+}$locus. The hypotheses of linkage and independent assortment were tested with $\chi^{2}$ analyses. Males carrying $s^{a l-s}$ were mated to females carrying $s^{a l-s}$ and the resulting $s^{a l-s} / s^{a l-c}$ males were crossed to Rhode Island Red, Barred Plymouth Rock and albino layer line hens. Heterogeneity $\chi^{2}$ analysis of the data from these three crosses allowed pooling of the data using either hypothesis.

Individuals mosaic for ocular pigmentation resulted from a number of matings. Although nearly all died mid-way through incubation, they were not observed until unhatched eggs were opened after 22 of incubation. The occurrence and approximate time of death was recorded for all mosaic embryos, as was the sex. of 9 and the distribution of pigment in the eyes of 37. Mutation frequency was determined as the number of mosaics divided by the total of albinos plus mosaics. The frequency per mutation opportunity adjusted this data to account for albino females having only one $\mathrm{Z}$ chromosome, and thus only one opportunity for mutation, while albino males have two.

\section{RESULTS}

Table I presents segregation data from matings involving $s^{a l-s}$. In matings between albinos, 15 non-albino individuals were observed; this is probably too many to be explained by pedigree errors. In the three matings where both genotypes were expected among the progeny, a slight deficiency of albinos was observed which was not explained by consistent differences in fertility or early embryonic mortality. This difference was significant in only one mating and was largely the result of a difference in one of the 16 data sets pooled to obtain the totals shown. In this mating, $23.3 \%$ of offspring were albino (25\% expected), and in the exceptional data set, $22.1 \%$ 
were albino. Both of these suggest a ratio of $1: 3$ albino and non-albino individuals. The cross between homozygous non-albino males and non-albino females produced two albino individuals, probably the result or pedigree errors.

The four crosses expected to produce albino offspring all produced a low incidence of individuals which were mosaic for ocular pigmentation (table I). This was observed as an area of pigment on an otherwise colorless eye. No mosaic individuals were observed in over 900 offspring of the crosses not expected to produce albinos, suggesting that mosaics were the result of albino melanocytes becoming capable of producing pigment, rather than the reverse.

Sex ratio (table II) produced by these matings were very close to those expected from a sex-linked recessive gene. Four unexpected individuals (1 albino male and 3 non albino females) may have been the result of pedigree errors or misclassification.

Table II. Segregation data resulting from albino trials in which sex was determined ${ }^{\mathbf{1}}$.

\begin{tabular}{|c|c|c|c|c|c|c|c|c|c|c|}
\hline \multirow{3}{*}{$\begin{array}{l}\text { Mating } \\
s^{a l} s^{a l} \times s^{a l} /-\end{array}$} & \multicolumn{4}{|c|}{ Albino } & \multicolumn{4}{|c|}{ Non-albino } & \multirow[t]{2}{*}{ Total } & \multirow[t]{2}{*}{$\chi^{2}$} \\
\hline & \multicolumn{2}{|r|}{ Male } & \multicolumn{2}{|c|}{ Female } & \multicolumn{2}{|c|}{ Male } & \multicolumn{2}{|c|}{ Female } & & \\
\hline & 267 & $(268)^{2}$ & 268 & $(268)$ & 0 & $(0)$ & 0 & $(0)$ & 535 & 0.00 \\
\hline$s^{a l} s^{a l} \mathrm{X}+1-$ & 1 & $(0)$ & 391 & $(401)$ & 411 & $(401)$ & 3 & $(0)$ & 806 & 0.50 \\
\hline$+s^{a l} \times s^{a l} /-$ & 669 & $(668)$ & 663 & $(668)$ & 669 & $(668)$ & 671 & $(668)$ & 2672 & 0.06 \\
\hline$+s^{a l} \mathrm{X}+1-$ & 0 & (0) & 310 & $(320)$ & 654 & (641) & 319 & $(320)$ & 1283 & 0.61 \\
\hline \multirow{3}{*}{$\begin{array}{l}++\mathrm{X} s^{a l} /- \\
++\mathrm{X}+/-\end{array}$} & 0 & $(0)$ & 0 & (0) & 20 & (18) & 16 & (18) & 36 & 0.44 \\
\hline & 0 & (0) & 0 & (0) & 43 & $(45)$ & 46 & $(45)$ & 89 & 0.10 \\
\hline & 937 & & 1634 & & 1797 & & 1055 & & 5421 & \\
\hline
\end{tabular}

${ }^{1}$ The symbol + is used to indicate both $S$ and $s^{+}$alleles. ${ }^{2}$ Numbers in brackets represent the values expected with a sex-linked recessive gene.

The results of mating $S / s^{a l-s}$ males to albino and gold females are shown in table III. Expected values take into account that $s^{\text {al-s }}$ came from a stock homozygous for $s^{+}$and the albino parents would be expected to carry $s^{+}$in a cryptomeric form if the genes reside at separate loci. Chi-square analyses showed that the results differed from both hypotheses. However, the $\chi^{2}$ value for the hypothesis of linkage was much smaller than that for independant assortment. A similar situation was observed when heterozygous males were mated to gold females.

Mating males heterozygous for $s^{a l-c}$ to females hemizygous for $s^{a l-s}$ produced 141 embryos. Allelic genes should produce a 1:1:1:1 ratio of albino and non-albino males and females, and complementation of unlinked genes should result in a 1:2:1 ratio of albino females, non-albino males and non-albino females, with no males. The observed numbers were 38:32:36:35 and $\chi^{2}$ analysis showed that these fit a 1: $1: 1: 1$ ratio $\left(\chi^{2}=0.53,3 \mathrm{df}, P<0.90\right)$, but not a $1: 2: 1$ ratio $\left(\chi^{2}=9.44,2 \mathrm{df}\right.$, $P<0.01)$.

Results of mating males heterozygous for $s^{a l-c}$ and $s^{a l-s}$ to females hemizygous for $s$ (Rhode Island Reds and females from the albino line) or $S$ (Barred Plymouth Rocks) are shown in table IV. Again, hypothesis of both linkage and independent 
Table III. Results of crossing S/s $s^{a l-s}$ males to $s^{a l-s} /-$ and $s^{+} /-$with $\chi^{2}$ analyses based on two hypotheses.

\begin{tabular}{|c|c|c|c|c|c|c|c|c|}
\hline & \multicolumn{2}{|c|}{ Silver } & \multicolumn{2}{|r|}{ Gold } & \multicolumn{2}{|c|}{ Albino } & \multirow[t]{2}{*}{ Total } & \multirow[t]{2}{*}{$\chi^{2}$} \\
\hline & Male & Female & Male & Female & Male & Female & & \\
\hline \multicolumn{9}{|l|}{ Observed } \\
\hline $\mathrm{X} s^{a l-s} /-$ & 49 & 38 & 0 & 0 & 23 & 34 & 144 & \\
\hline $\mathrm{X} s^{+} /-$ & 20 & 39 & 41 & 1 & 0 & 36 & 137 & \\
\hline \multicolumn{9}{|l|}{$\begin{array}{l}\text { Expected } \\
\text { Allelic }\end{array}$} \\
\hline$\times s^{a l-s} /-^{1}$ & 36 & 36 & 0 & 0 & 36 & 36 & 144 & $9.61^{*}$ \\
\hline $\mathrm{X} s^{+} /-^{2}$ & 34 & 34 & 34 & 0 & 0 & 34 & 136 & $8.06^{*}$ \\
\hline \multicolumn{9}{|l|}{ Independent } \\
\hline $\mathrm{X} s^{a l-s} /-^{3}$ & 18.0 & 18.0 & 18.0 & 18.0 & 36.0 & 36.0 & 144 & $116.42^{* *}$ \\
\hline $\mathrm{X} s^{+} /-^{4}$ & 34.3 & 17.1 & 34.3 & 17.1 & 0 & 34.3 & 137 & $50.47^{* *}$ \\
\hline
\end{tabular}

${ }^{1}$ Expected 1:1:0:0:1:1 ratio; ${ }^{2}$ Expected 1:1:1:0:0:1 ratio; ${ }^{3}$ Expected 1:1:1:1:2:2 ratio; ${ }^{4}$ Expected 2: 1: 2: 1: 0: 2 ratio; ${ }^{*} P<0.05 ;{ }^{* *} P<0.01$.

Table IV. Results of crossing $s^{a l-c} / s^{a l-s}$ males to $S /-$ and $s^{+} /-$females with $\chi^{2}$ analysis based on two hypothesis.

\begin{tabular}{|c|c|c|c|c|c|c|}
\hline & \multicolumn{2}{|c|}{ Albino } & \multicolumn{2}{|c|}{ Non-albino } & \multirow[t]{2}{*}{ Total } & \multirow[t]{2}{*}{$\chi^{2}$} \\
\hline & Male & Female & Male & Female & & \\
\hline Observed & 1 & 368 & 399 & 2 & 770 & \\
\hline \multicolumn{7}{|l|}{ Expected } \\
\hline Allelic ${ }^{1}$ & 0 & 383.5 & 383.5 & 0 & 767 & 1.25 \\
\hline Independent ${ }^{2}$ & 0 & 288.4 & 384.5 & 96.1 & 769 & $114.70^{* *}$ \\
\hline
\end{tabular}

${ }^{1}$ Expected 0: 1: 1:0 ratio; ${ }^{2}$ Expected 0: 3:4:1 ratio; ${ }^{* *} P<0.01$.

assortment were tested. The data were found to fit a 1:1 ratio, expected with alleleism of the genes, but not a 3:4: 1 ratio.

Table IV shows the occurrence of embryos mosaic for ocular pigmentation observed among the offspring of 15 matings. Mosaics appeared to be albino except that one or both eyes contained a variable amount of pigment. The 15 embryos classified as non-albino produced from matings of albino males to albino females were thought to be mosaics with extensive areas of pigmentation. No attempt was made to record mosaicism of feather pigmentation since mosaic embryos died soon after feather growth began, the embryos were not observed until after 22 days of incubation (8-12 days after death) and the genes $c$ and $I$ segregated of these populations producing white down on non-albino individuals. The frequency of 
observed mosaics per mutation opportunity ranged from 0.52 to $4.87 \%$. The data sets were classified into those involving the albino meat line, those involving the albino layer line, and those involving $s^{a-c}$. There were no clear differences between the 3 groups and the frequency of mosaics observed per mutation opportunity was $1.93 \%$ in combined matings.

Table V. Mosaic embryos from 15 crosses involving the albino gene ${ }^{1}$

\begin{tabular}{|c|c|c|c|c|c|c|c|c|}
\hline \multirow[b]{2}{*}{ Cross } & \multirow[b]{2}{*}{ Line $e^{2}$} & \multirow[b]{2}{*}{ Albino } & \multirow[b]{2}{*}{ Mosaic } & \multirow[b]{2}{*}{$M / A+M^{3}$} & \multirow[b]{2}{*}{$M / M u t O p^{4}$} & \multicolumn{3}{|c|}{ Sex } \\
\hline & & & & & & $M$ & $F$ & ? \\
\hline$+/ s^{a l-s} \mathrm{X}+/-$ & M & 282 & 9 & 3.09 & 3.09 & - & - & $\mathbf{9}$ \\
\hline$+/ s^{a l-s} \mathrm{X}+1-$ & M & 47 & 1 & 2.08 & 2.08 & - & - & 1 \\
\hline$+/ s^{a l-s} \times s^{a l-s} /+$ & $\mathbf{M}$ & 255 & 2 & 0.78 & 0.52 & - & - & 2 \\
\hline$s^{a l-s} / s^{a l-s} \times s^{a l-s} /+$ & $M / L$ & 165 & $13^{5}$ & 7.30 & 4.87 & - & - & 13 \\
\hline$+/ s^{a l-s} \times s^{a l-s} /-$ & $\mathrm{M}$ & 338 & 9 & 2.59 & 1.73 & - & 1 & 8 \\
\hline$+\mid s^{a l-s} \times s^{a l-s} /-$ & $\mathbf{M}$ & 549 & 9 & 1.61 & 1.08 & 3 & 3 & 3 \\
\hline$+/ s^{a l-s} \times s^{a l-s} /-$ & M & 105 & 5 & 4.55 & 3.03 & - & - & 5 \\
\hline$+/ s^{a l-s} \mathrm{X}+/-$ & $\mathbf{M}$ & 47 & 1 & 2.08 & 2.08 & - & 1 & 0 \\
\hline$s^{a l-s} / s^{a l-s} \mathrm{X}+1-$ & $\mathbf{L}$ & 75 & 1 & 1.32 & 1.32 & - & - & 1 \\
\hline$s^{a l-s} / s^{a l-s} \times s^{a l-s} /-$ & $\mathbf{L}$ & 388 & $14^{6}$ & 3.48 & 2.32 & - & 1 & 13 \\
\hline$+/ s^{a l-s} \times+/-$ & L & 45 & 2 & 4.26 & 4.26 & - & - & 2 \\
\hline$+/ s^{a l-s} \times s^{a l-s} /-$ & $\mathrm{L}$ & 118 & 1 & 0.84 & 0.56 & - & - & 1 \\
\hline$+\mid s^{a l-c} \times s^{a l-s} /-$ & UM & 72 & 3 & 4.00 & 2.67 & - & - & 3 \\
\hline$s^{a l-c} / s^{a l-s} \mathrm{X}+/-$ & UM & 198 & 3 & 1.49 & 1.49 & - & - & 3 \\
\hline$s^{a l-c} / s^{a l-s} \mathrm{X}+/-$ & UM & 59 & 1 & 1.67 & 1.67 & - & - & 1 \\
\hline & & 2743 & 74 & 2.70 & 1.93 & 3 & 6 & 65 \\
\hline
\end{tabular}

${ }^{1}$ The symbol + is used to indicate both $S$ and $s^{+}$alleles; ${ }^{2} \mathrm{M}$ represents the meat line; L, the layer line; and UM, crosses involving the gene from the University of Massachusetts; ${ }^{3}$ (number of mosaics/albino + mosaic embryos) $\times 100 ;{ }^{4}$ (number of mosaics/mutation opportunities) $\times 100 ;{ }^{5}$ Includes 7 non-albino individuals; ${ }^{6}$ Includes 8 non-albino individuals.

The distribution of the pigment on 37 of the mosaics was observed. More pigment was seen on the right side of 31 embryos, on the left side of 4 and the pigment on 2 others was deposited approximately equally on both sides. Sixty-four of the embryos died between 9 and 15 days of incubation, 7 died before this time and only 3 survived longer; none hatched. The sex of 9 mosaic individuals was determined surgically. Three were male and the rest were female. One female was from a cross expected to produce only albino females and the other mosaics were from crosses expected to produce albinos of both sexes. 


\section{DISCUSSION}

It is clear from these data that $s^{a l}$ is sex-linked and recessive. Six mating combinations, comprised of 47 crosses made over a period of several years and involving different populations, resulted in the genotype of 9637 individuals and the sex of 5421 of these being determined. The results were very close to those expected.

Crosses were made to determine the relationship of $s^{a l-s}$ to the $s^{+}$locus. Males heterozygous for $S$ and $s^{a l-s}$ were crossed to $s^{a l-s}$ and $s$ females. While results differed from those expected with both allelism and independant assortment of the genes, $\chi^{2}$ values for the hypothesis of allelism were small. Linkage does not explain the observed difference from expectations using either hypothesis, since the observed results did not fall between the expectations, and were closer to those expected with allelism of the genes. In addition, linkage would be expected to produce deviations from expected in the same phenotypic classes and in the same direction for both crosses, a result which was not observed. The deviation from the ratio expected with allelic genes is probably due to chance, although misclassification cannot be ruled out. Allelism of $s^{a l-s}$ and $s^{a l-c}$ confirmed the location of $s^{a l-s}$ to the $s^{+}$locus.

One consistent observation among the crosses expected to produce albinos was a slight deficiency of the mutants. This deficiency, the occurrence of mosaic embryos, and the large number of mutations to sex-linked imperfect albinism in various avian species could all be explained if the mutation was the result of integration of a movable genetic element into or near the $s^{+}$locus.

McClintock described such elements in maize (Fincham and Sastry, 1974) and they have since been well documented in maize, bacteria, yeast and drosophila (Calos and Miller, 1980; Whitney and Lamoreux, 1982). Bingham and Judd (1981) proposed that the $w^{a}$ mutation in Drosophila resulted from the insertion of the copia element into the fly's genome but not into the peptide coding region, producing a mutant phenotype which is near-white with eyes containing a substantial amount of pigment. Such polar effects have also been described for bacterial insertion elements (Nevers and Saedler, 1977). Jenkins et al (1981) suggested that the dilute $(d)$ coat color mutation of mice may be the result of viral DNA integration. Bacon et al (1988) suggested that the $K$ mutation in chickens could also be the result of viral integration since $K$ and $e v 21$ are tightly linked and because females in slowfeathering strains of White Leghorns infrequently revert to the rapid-feathering phenotype. Unstable genetic elements have been implicated or proposed to explain pigment mosaics in plants (Groose et al, 1988; Smith et al, 1988), mice (Witney and Lamoreux, 1982) and dogs (Sponenberg, 1984). The mutations alter the pigmentation and random somatic reversions to wild-type produce areas of normal color. Somatic reversions to wild-type affected 5.3 to $46.5 \%$ of mice with various mutant phenotypes (Whitney and Lamoreux, 1982) and 1.8 to $4.8 \%$ of merle dogs (Sponenberg, 1984).

Somatic reversion in a small percentage of imperfect albino embryos could explain the slight deficiency of albinos, since all mosaics were presumably albino. The rate of reversion is comparable to that found in mice and dogs, keeping in mind that classification of mosaics here was only on the basis of ocular pigmentation, some mosaics were classified as non-albino (3.9 and $2.0 \%$ in 2 sets of matings involving only albino parents), and that albino females had only 1 sex chromosome. The 
phenotype of mosaics is similar to that of a number of organisms carrying unstable elements and the production of some pigment by mutant birds suggests that a sequence is inserted near the locus rather than into it.

Mutations to sex-linked imperfect albinism are common in avian species. The gene is sex-linked and the phenotype is dramatic in a colored population, so that new mutations are easily seen. Nevertheless, random integration of a sequence providing this number of apparently identical mutations would be at a level that would cause havoc with the remainder of the genome and would appear to be unlikely. Most insertion elements are at least moderately specific in their site of integration (Calos and Miller, 1980). Tereba (1983) reported that 6 of $10 \mathrm{ev}$ loci localized in the genome of the chicken have been found on chromosome I and suggested preferred integration sites of the $e v$ DNA as one possible explanation. An insertion sequence may have a preferred site of integration in the avian genome at or near the $s^{+}$locus, or an insertion element may reside at a suitable distance from the the locus to transpose easily into or near to it. Somes (1984) shows many mutant genes, including $\mathrm{K}$, in this region of the sex chromosome of the chicken, supporting the latter hypothesis. Rates of reversion in crosses involving the albino layer line, the albino meat line and $s^{a l-c}$ were very similar, suggesting that this is independent of the genetic background of the birds, and that if insertion elements are involved, they are similar for $s^{a l-s}$ and $s^{a l-c}$ and are inserted in similar places.

\section{ACKNOWLEDGMENT}

The authors with to express gratitude to $\mathrm{P}$ Mérat for providing the French translations.

\section{REFERENCES}

Bacon LD, Smith EJ, Crittenden LB (1988) Association of slow feathering $(K)$ and an endogenous viral (ev21) gene on the Z chromosome of chickens. Poult Sci 67, 191-197

Bingham PM, Judd BH (1981) A copy of the copia transposable element is very tightly linked to the $w^{a}$ allele at the white locus of D. melanogaster. Cell 25, 705-711 Bruckner JH (1969) Sex-linked, subvital incomplete albinism in phasianus colchicus. Poult Sci 48, 1791

Calos MP, Miller JH (1980) Transportable elements. Cell 20, 579-595

Champion LR (1958) The inheritance of imperfect albinism in the fowl. Quart Bull Mich Agr Exp Sta 41, 237-245

Dodwell GT (1976) Encyclopedia of Canaries TFH Publications, Hong-Kong Fincham JRS, Sastry GRK (1974) Controlling elements in maize. Ann Rev Genet 8, 15-50

Groose RW, Weigelt HD, Palmer RG (1988) Somatic analysis of an unstable mutation for anthrocyanin pigmentation in soybean. J. Hered 79, 263-267

Hutt FB, Mueller CD (1942) Sex-linked albinism in the turkey. $J$ Hered 33, 69-77 Hutt FB, Mueller CD (1943) Independent identical mutations to albinism in the sex chromosome of the fowl. Am Nat 77, 181-184 
Jenkins NA, Copeland NG, Taylor BA, Lee BK (1981) Dilute $(d)$ coat color mutation of $\mathrm{DBA} / 2 \mathrm{~J}$ mice is associated with the site of integration of an ecotropic MuLV genome. Nature 293, 370-374

Lauber J (1964) Sex-linked albinism in the Japanese quail. Science 146, 948-950

Mueller CD, Hutt FB (1941) Genetics of the fowl. 12. Sex-linked imperfect albinism. $J$ Hered 32, 71-80

Nevers P, Saedler H (1977) Transposable genetic element as agents of gene instability and chromosomal rearrangements. Nature 268, 109-115

Silversides FG, Crawford RD (1990a) Effects of imperfect albinism $\left(s^{a l-s}\right)$ on growth in a heavy line of chicken Poult Sci (in press)

Silversides FG, Crawford RD (1990b) Effects of imperfect albinism $\left(s^{a l-s}\right)$ on egg production in two lines of chicken Poult Sci (in press)

Sittman K, Wilson WO, McFarland LZ (1986) Buff and albino Japanese quail. $J$ Hered 57, 119-124

Smith MAL, Spomer LA, Cowen RKD (1988) Image analysis to quantify the expression of an unstable allele. $J$ Hered $79,147-150$

Somes RG Jr (1984) International Registry of Poultry Genetic Stocks. University of Connecticut, Storrs

Sponenberg DP (1984) Germinal reversion of the merle allele in Australian shepherd dogs. $J$ Hered 75, 78

Strickberger MW (1976) Genetics. MacMillan Publishing Co Inc, New York

Tereba A (1983) Asymmetric chromosomal distribution of endogenous retroviral loci in chickens and mice. Curr Top Microbiol Immunol 107, 29-50

Werret WF, Candy AJ, King JOL, Sheppard PM (1959) Semi-albino: a third sexlinked allelomorph of silver and gold in the fowl. Nature 184, 480

Whitney JB III, Lamoreux ML (1982) Transposable elements controlling genetic instabilities in mammals. $J$ Hered $73,12-18$ 